\title{
Evolution of features of chronic pancreatitis during endoscopic ultrasound-based surveillance of individuals at high risk for pancreatic cancer
}

다(1) $(9)$

\author{
Authors \\ Marco J. Bruno ${ }^{1}$ \\ Institutions \\ 1 Department of Gastroenterology and Hepatology, \\ Erasmus MC, University Medical Center Rotterdam, \\ Rotterdam, The Netherlands \\ 2 Department of Gastroenterology and Hepatology, \\ Academic Medical Center, Amsterdam, The Netherlands
}

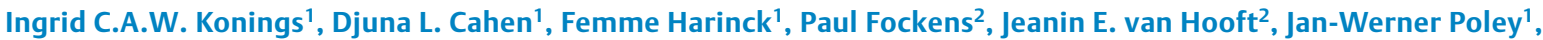

submitted 22.6.2017

accepted after revision 25.10.2017

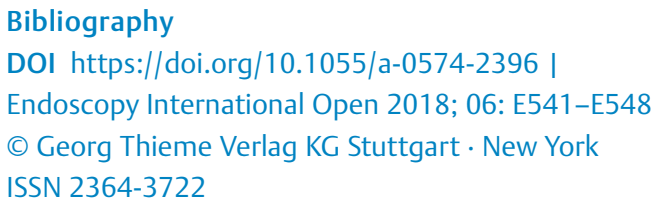

Corresponding author

Ingrid C.A.W. Konings, Erasmus MC, University Medical Center Rotterdam, P.O. Box 2040, 3000 CA Rotterdam, The Netherlands

Fax: +31-10-70-30331

i.konings@erasmusmc.nl

\section{ABSTRACT}

Background and study aims During endoscopic ultrasound (EUS)-based pancreatic ductal adenocarcinoma (PDAC)-surveillance in asymptomatic individuals, features of chronic pancreatitis (CP) are often detected. Little is known about the prevalence and progression of these features. The aim of this study was to quantify these features, assess the interobserver agreement, assess possible associated factors, and assess the natural course during 3 years of follow-up.

Patients and methods Two experienced endosonographers reviewed anonymized sequential EUS videos of participants in PDAC surveillance that were obtained in 2012 and 2015 for features of CP. Descriptives, agreement analyses, univariate and multivariate analyses for possible risk factors, and repeated measures analyses to assess intra-individual changes over time were performed.

Results A total of 42 EUS videos of 21 participants were reviewed. Any feature of CP was present in $86 \%$ (2012) and $81 \%$ (2015) of participants, with a mean of 2.5 features per individual. The overall interobserver agreement was almost perfect at $83 \%$. No baseline factors were significantly associated with features of CP. Features did not change over time, except for hyperechoic foci without shadowing, which decreased intra-individually $(\beta=-1.6, P=0.005)$.

Conclusions This blinded study shows features of $\mathrm{CP}$ to be highly prevalent in individuals at high risk of developing pancreatic cancer. No baseline factors were associated with presence of these features. CP features did not increase intra-individually over a 3-year period. Longer follow-up and pathological examination of pancreatic resection specimens will be essential to learn whether EUS detection and follow-up of these CP features bear clinical relevance.

\section{Introduction}

Over the past decades, multiple centers have initiated surveillance programs in individuals at high risk of developing pancreatic ductal adenocarcinoma (PDAC) to evaluate the diagnostic yield of such surveillance programs and ultimately improve poor survival of PDAC [1 - 13]. As recommended by the Cancer of the Pancreas Screening (CAPS) Consortium, most surveillance programs entail annual magnetic resonance imaging (MRI) as well as endoscopic ultrasound (EUS) imaging of the pancreas [14]. The diagnostic yield for detection of high-grade dysplastic precursor lesions (i. e., pancreatic intraductal neoplasia (PanIN)-3 and intraductal papillary mucinous neoplasms (IPMN) with high-grade dysplasia) or early stage PDAC varies between studies with an overall diagnostic yield of about $10 \%$ [15].

During EUS-based PDAC surveillance, cystic or solid lesions can be detected and features of chronic pancreatitis (CP) also are frequently observed. The clinical significance of these $C P$ features in asymptomatic individuals is still unclear. Research 
suggests that these features might be related to emerging PanIN and IPMN lesions [16,17], however, little is known about the prevalence and progression of these CP features detected in asymptomatic high-risk individuals. Therefore, the aim of this study was to quantify CP features in individuals participating in our EUS/MRI-based surveillance program by reviewing stored videos of sequential EUS examinations and assess their progress over a 3-year period. We also aimed to study interobserver agreement in our series and assess possible factors associated with presence of these CP features.

\section{Patients and methods}

Our PDAC surveillance program has been described in detail before [13]. In summary, annual surveillance is performed using EUS and MRI/MRCP in individuals at inherited or familial increased risk of developing PDAC ( $\geq 10 \%$ life-time risk, i. e. all carriers of CDKN2A gene mutations, all Peutz-Jeghers syndrome patients, carriers of gene mutations in BRCA1, BRCA2, TP53 or mismatch repair genes with a family history of PDAC in at least two family members, and first-degree relatives of patients with familial pancreatic cancer [FPC]). All EUS-investigations are performed under conscious sedation with midazolam/fentanyl by experienced endosonographers using a curvilinear device. Images of the pancreas are obtained from the duodenum and stomach and are digitally recorded in real time with lossy compression.

For this study, all participants in PDAC surveillance at the Erasmus University Medical Center Rotterdam, The Netherlands, were included for whom two EUS videos were available 3 years apart (2012 and 2015). The images were anonymized for patient ID and date of investigation. Two highly experienced endosonographers (MB and JWP, each over 3500 career EUS investigations) individually reassessed the videos for features of CP: parenchymal features [18] were scored in the head, body and tail of the pancreas and ductal features [18] were scored in the body and tail, using a standardized Case Record Form. The EUS videos were randomly assigned a video number and were thus assessed in an order for which no correlation could be made between patient ID or date of investigation. Both endosonographers scored the videos separately, after which a consensus meeting was held to discuss individuals in whom there was a difference in scored features.

The study was approved by the local Ethical Committee and was conducted in accordance with the Declaration of Helsinki. All participants provided written informed consent prior to performance of any study procedures.

\section{Statistical methods}

Descriptive statistics were used to describe participants' characteristics. A proportion of agreement was calculated to assess interobserver agreement for each feature of CP. We considered an agreement of 0.00 as poor, $0.01-0.20$ as slight, $0.21-0.40$ as fair, $0.41-0.60$ as moderate, $0.61-0.80$ as substantial and $0.81-0.99$ as almost perfect agreement and 1.00 as perfect agreement [19].
Data after consensus agreement were analyzed using descriptive statistics and univariate (Chi-square test, Fisher's exact test and independent $t$-test where appropriate) and multivariate analyses, to detect participants' characteristics associated with a mean of $\geq 4$ CP features on EUS assessments. Intra-individual changes over time were assessed with repeated measures, generalized estimated equations for ordinal outcomes, and with mixed-effect models (growth curve models) with maximum likelihood estimator and unstructured covariance matrix for longitudinal data (non-proportional analyses). To correct for multiple testing, we only report $P$ values $<0.01$ as statistically significant. For all statistical analyses, the Statistical Package for the Social Sciences was used (version 23.0, SPSS Institute, Chicago, IL).

\section{Results}

\section{Participant characteristics}

In 2012, EUS videos of 26 individuals participating in surveillance were stored, of whom 21 individuals had a follow-up EUS video available in 2015. These 21 individuals were included in the study and their characteristics are summarized in $>$ Table 1. The mean age of the 21 included individuals was 52, they were predominantly female and there were no excessive alcohol consumers or diabetic participants.

Review of the first EUS video showed any feature of chronic pancreatitis in 18 of 21 (86\%) participants, and in 17 (81\%) at review of the second video, 3 years later (as specified in $>\mathbf{T a}$ ble 2). The mean number of CP features per participant was 2.5 (range $0-7$ ). When the Rosemont classification [18] was applied, only $52 \%$ of screened individuals had a normal EUS examination and three (7\%) fulfilled criteria for CP.

\section{Interobserver agreement}

Results of the interobserver agreement analyses are shown in - Table 3. On almost all CP features, there was an almost perfect to perfect agreement between the two reviewers. Substantial agreement was reached for hyperechoic foci without shadowing overall (69\% agreement), in the head (69\% agreement) and in the tail of the pancreas (79\% agreement)), for lobularity without honeycombing overall (71\% agreement) and in the body of the pancreas (71\% agreement), and for hyperechoic main pancreatic duct margins overall (71\% agreement), and in the body of the pancreas (79\% agreement). Only moderate agreement was reached for stranding overall, and in the head of the pancreas (59.5 and $52.4 \%$ agreement, respectively). Agreement for all CP features (taken together, all possible CP features in any location of the pancreas, i. e. the 29 items from - Table 3) rated as almost perfect at $83 \%$.

\section{Characteristics associated with features of chronic pancreatitis}

- Table 4 shows the results of univariate and multivariate analyses regarding possible risk factors associated with detection of a mean of $\geq 4$ features of CP on EUS. On univariate analysis, "age of the youngest relative affected by PDAC" was the only 
- Table 1 Baseline characteristics of included individuals.

\begin{tabular}{|c|c|}
\hline & $\begin{array}{l}\text { All individuals included in the study }(n=21) \\
\mathrm{N}(\%)\end{array}$ \\
\hline Sex, male & $4(19 \%)$ \\
\hline Age at inclusion (years), mean (range, SD) & $52(41-68,7.1)$ \\
\hline Body Mass Index, mean (range, SD) & $26(16-40,5.4)$ \\
\hline \multicolumn{2}{|l|}{ Underlying gene mutation } \\
\hline - CDKN2A mutation & $6(29 \%)$ \\
\hline - BRCA2 mutation & $1(5 \%)$ \\
\hline - LKB1/STK11 mutation & $1(5 \%)$ \\
\hline . Unknown (FPC) & $13(62 \%)$ \\
\hline No. of relatives affected by PDAC, mean (range, SD) & $2(0-6,1.5)$ \\
\hline Age of youngest relative affected by PDAC, mean (range, SD) & $50(42-72,9.1)$ \\
\hline Diabetes & $0(0 \%)$ \\
\hline \multicolumn{2}{|l|}{ Smoking } \\
\hline - Current smoker & $3(14 \%)$ \\
\hline - Past smoker & $3(14 \%)$ \\
\hline - Never smoker & $15(71 \%)$ \\
\hline - $\geq 20$ pack years of smoking & $3(14 \%)$ \\
\hline \multicolumn{2}{|l|}{ Alcohol consuming } \\
\hline - Current alcohol consumer & $16(76 \%)$ \\
\hline - Current excessive alcohol consumer ( $\geq 3$ units/day) & $0(0 \%)$ \\
\hline - Past alcohol consumer & $1(5 \%)$ \\
\hline - Past excessive alcohol consumer ( $\geq 3$ units/day) & $0(0 \%)$ \\
\hline - Never alcohol consumer & $4(19 \%)$ \\
\hline \multicolumn{2}{|l|}{ Features of chronic pancreatitis } \\
\hline - Individuals with features present at first available EUS video & $18(86 \%)$ \\
\hline - Individuals with features present at second available EUS video & $17(81 \%)$ \\
\hline
\end{tabular}

identified risk factor ( $P=0.002)$, but it was not sustained after multivariate analysis.

\section{Intra-individual change in detected features of chronic pancreatitis}

Results of the repeated measures generalized estimated equations analyses of intra-individual change in CP features are shown in > Table 2. Except for hyperechoic foci without shadowing, which decreased intra-individually (overall ( $\beta=-1.6$, standard error [SE] 0.6, $P=0.006$ ) and, more specifically, in the head of the pancreas $(\beta=-2.1$, SE $0.7, P=0.005)$, CP features did not change in the 3 years. Also, the mean number of $C P$ features and the Rosemont classification did not change. However, there was one individual, a 60-year-old woman without a known gene mutation (FPC), in whom in 2012 only 1 feature of CP was present (a cyst in the head of the pancreas), while in
2015, no less than 7 features were detected (hyperechoic foci with and without shadowing, lobularity with and without honeycombing, stranding, MPD calculi, and hyperechoic MPD margins) ( $\triangleright$ Fig. 1). Unfortunately, this patient subsequently died of trauma.

None of the individuals in this series underwent surgery between 2012 and 2015. One individual, a 50-year-old male without a known gene mutation (FPC), had already undergone a distal pancreatectomy in 2011 as a consequence of two EUS-detected solid lesions. Prior to surgery, no features of CP were detected. The resection specimen harbored a panIN-2 lesion and diffuse foci with panIN-1B. The EUS videos of the remnant pancreas from 2012 and 2015 showed hyperechoic foci without shadowing and hyperechoic MPD margins in 2012; in 2015 only, stranding was detected. 
- Table 2 Overview of detected features of chronic pancreatitis.

\begin{tabular}{|c|c|c|c|c|c|c|}
\hline \multirow[t]{2}{*}{ Features of chronic pancreatitis } & \multirow[t]{2}{*}{$\begin{array}{l}\text { All available EUS } \\
\text { videos }(n=42)\end{array}$} & \multirow{2}{*}{$\begin{array}{l}\text { First available } \\
\text { EUS video } \\
(2012, n=21)\end{array}$} & \multirow{2}{*}{$\begin{array}{l}\text { Second available } \\
\text { EUS video } \\
(2015, n=21)\end{array}$} & \multicolumn{3}{|c|}{$\begin{array}{l}\text { Intra-individual change } \\
\text { (2012 vs 2015) }\end{array}$} \\
\hline & & & & B & SE & $P$ \\
\hline $\begin{array}{l}\text { Hyperechoic foci with shadowing } \\
\text { " Head } \\
\text { " Body } \\
\text { " Tail }\end{array}$ & $\begin{array}{l}3(7 \%) \\
1(2 \%) \\
3(7 \%) \\
2(5 \%)\end{array}$ & $\begin{array}{l}2(10 \%) \\
0(0 \%) \\
2(10 \%) \\
1(5 \%)\end{array}$ & $\begin{array}{l}1(5 \%) \\
1(5 \%) \\
1(5 \%) \\
1(5 \%)\end{array}$ & $\begin{array}{l}-0.74 \\
- \\
-0.74 \\
-\end{array}$ & $\begin{array}{l}1.3 \\
- \\
1.3 \\
-\end{array}$ & $\begin{array}{l}0.570 \\
- \\
0.570 \\
1.000\end{array}$ \\
\hline $\begin{array}{l}\text { Hyperechoic foci without shadowing } \\
\text { - Head } \\
\text { - Body } \\
\text { - Tail }\end{array}$ & $\begin{array}{r}20(48 \%) \\
15(36 \%) \\
10(24 \%) \\
8(19 \%)\end{array}$ & $\begin{array}{r}14(67 \%) \\
12(57 \%) \\
8(38 \%) \\
5(24 \%)\end{array}$ & $\begin{array}{l}6(29 \%) \\
3(14 \%) \\
2(10 \%) \\
3(14 \%)\end{array}$ & $\begin{array}{l}-1.61 \\
-2.08 \\
-1.77 \\
-0.63\end{array}$ & $\begin{array}{l}0.6 \\
0.7 \\
0.8 \\
0.8\end{array}$ & $\begin{array}{l}0.006 \\
0.005 \\
0.035 \\
0.414\end{array}$ \\
\hline $\begin{array}{l}\text { Lobularity with honeycombing } \\
\text { - Head } \\
\text { - Body } \\
\text { - Tail }\end{array}$ & $\begin{array}{l}5(12 \%) \\
1(2 \%) \\
5(12 \%) \\
4(10 \%)\end{array}$ & $\begin{array}{l}3(14 \%) \\
1(5 \%) \\
3(14 \%) \\
2(10 \%)\end{array}$ & $\begin{array}{l}2(10 \%) \\
0(0 \%) \\
2(10 \%) \\
2(10 \%)\end{array}$ & $\begin{array}{l}-0.46 \\
- \\
-0.46 \\
-\end{array}$ & $\begin{array}{l}0.8 \\
- \\
0.8 \\
-\end{array}$ & $\begin{array}{l}0.564 \\
- \\
0.564 \\
1.000\end{array}$ \\
\hline $\begin{array}{l}\text { Lobularity without honeycombing } \\
\text { - Head } \\
\text { - Body } \\
\text { - Tail }\end{array}$ & $\begin{array}{r}13(31 \%) \\
6(14 \%) \\
7(17 \%) \\
6(14 \%)\end{array}$ & $\begin{array}{l}8(38 \%) \\
4(19 \%) \\
5(24 \%) \\
2(10 \%)\end{array}$ & $\begin{array}{l}5(24 \%) \\
2(10 \%) \\
2(10 \%) \\
4(19 \%)\end{array}$ & $\begin{array}{l}-0.68 \\
-0.80 \\
-1.09 \\
0.80\end{array}$ & $\begin{array}{l}0.6 \\
0.8 \\
1.0 \\
0.8\end{array}$ & $\begin{array}{l}0.251 \\
0.318 \\
0.265 \\
0.318\end{array}$ \\
\hline $\begin{array}{l}\text { Cysts } \\
\text { - Head } \\
\text { " Body } \\
\text { " Tail }\end{array}$ & $\begin{array}{l}9(21 \%) \\
5(12 \%) \\
5(12 \%) \\
5(12 \%)\end{array}$ & $\begin{array}{l}5(24 \%) \\
2(10 \%) \\
3(14 \%) \\
3(14 \%)\end{array}$ & $\begin{array}{l}4(19 \%) \\
3(14 \%) \\
2(10 \%) \\
2(10 \%)\end{array}$ & $\begin{array}{l}-0.28 \\
0.46 \\
-0.46 \\
-0.46\end{array}$ & $\begin{array}{l}0.8 \\
1.0 \\
0.8 \\
0.8\end{array}$ & $\begin{array}{l}0.705 \\
0.656 \\
0.564 \\
0.564\end{array}$ \\
\hline $\begin{array}{l}\text { Stranding } \\
\text { - Head } \\
\text { - Body } \\
\text { - Tail }\end{array}$ & $\begin{array}{l}30(71 \%) \\
26(61 \%) \\
15(36 \%) \\
12(29 \%)\end{array}$ & $\begin{array}{r}14(67 \%) \\
12(57 \%) \\
6(29 \%) \\
5(24 \%)\end{array}$ & $\begin{array}{r}16(76 \%) \\
14(67 \%) \\
9(43 \%) \\
7(33 \%)\end{array}$ & $\begin{array}{l}0.47 \\
0.41 \\
0.63 \\
0.47\end{array}$ & $\begin{array}{l}0.6 \\
0.6 \\
0.5 \\
0.6\end{array}$ & $\begin{array}{l}0.411 \\
0.477 \\
0.167 \\
0.411\end{array}$ \\
\hline $\begin{array}{l}\text { MPD calculi } \\
\text { - Head } \\
\text { - Body } \\
\text { - Tail }\end{array}$ & $\begin{array}{l}1(2 \%) \\
1(2 \%) \\
0(0 \%) \\
0(0 \%)\end{array}$ & $\begin{array}{l}0(0 \%) \\
0(0 \%) \\
0(0 \%) \\
0(0 \%)\end{array}$ & $\begin{array}{l}1(5 \%) \\
1(5 \%) \\
0(0 \%) \\
0(0 \%)\end{array}$ & $\begin{array}{l}- \\
- \\
- \\
-\end{array}$ & $\begin{array}{l}- \\
- \\
- \\
-\end{array}$ & $\begin{array}{l}- \\
- \\
- \\
-\end{array}$ \\
\hline $\begin{array}{l}\text { Irregular MPD contour } \\
\text { - Body } \\
\text { - Tail }\end{array}$ & $\begin{array}{l}0(0 \%) \\
0(0 \%) \\
0(0 \%)\end{array}$ & $\begin{array}{l}0(0 \%) \\
0(0 \%) \\
0(0 \%)\end{array}$ & $\begin{array}{l}0(0 \%) \\
0(0 \%) \\
0(0 \%)\end{array}$ & $\begin{array}{l}- \\
- \\
-\end{array}$ & $\begin{array}{l}- \\
- \\
-\end{array}$ & $\begin{array}{l}- \\
- \\
-\end{array}$ \\
\hline $\begin{array}{l}\text { Dilated side branches } \\
\text { - Body } \\
\text { - Tail }\end{array}$ & $\begin{array}{l}5(12 \%) \\
2(5 \%) \\
5(12 \%)\end{array}$ & $\begin{array}{l}2(10 \%) \\
1(5 \%) \\
2(10 \%)\end{array}$ & $\begin{array}{l}3(14 \%) \\
1(5 \%) \\
3(14 \%)\end{array}$ & $\begin{array}{l}0.46 \\
- \\
0.46\end{array}$ & $\begin{array}{l}0.8 \\
- \\
0.8\end{array}$ & $\begin{array}{l}0.564 \\
1.000 \\
0.564\end{array}$ \\
\hline $\begin{array}{l}\text { MPD dilatation } \\
\text { - Body } \\
\text { - Tail }\end{array}$ & $\begin{array}{l}1(2 \%) \\
0(0 \%) \\
1(2 \%)\end{array}$ & $\begin{array}{l}0(0 \%) \\
0(0 \%) \\
0(0 \%)\end{array}$ & $\begin{array}{l}1(5 \%) \\
0(0 \%) \\
1(5 \%)\end{array}$ & $\begin{array}{l}- \\
- \\
-\end{array}$ & $\begin{array}{l}- \\
- \\
-\end{array}$ & $\begin{array}{l}- \\
- \\
-\end{array}$ \\
\hline $\begin{array}{l}\text { Hyperechoic MPD margin } \\
\text { - Body } \\
\text { - Tail }\end{array}$ & $\begin{array}{r}15(36 \%) \\
14(33 \%) \\
8(19 \%)\end{array}$ & $\begin{array}{l}8(38 \%) \\
7(33 \%) \\
4(19 \%)\end{array}$ & $\begin{array}{l}7(33 \%) \\
7(33 \%) \\
4(19 \%)\end{array}$ & $\begin{array}{l}-0.21 \\
- \\
-\end{array}$ & $\begin{array}{l}0.6 \\
- \\
-\end{array}$ & $\begin{array}{l}0.739 \\
1.000 \\
1.000\end{array}$ \\
\hline Mean number of features of CP (range, SD) & $2.5(0-7,1.5)$ & $2.7(0-5,1.4)$ & $2.2(0-7,2.2)$ & -0.43 & 0.4 & 0.328 \\
\hline $\begin{array}{l}\text { Rosemont classification } \\
\text { - Normal } \\
\text { - Indeterminate for CP } \\
\text { - Suggestive of CP } \\
\text { - Consistent with CP }\end{array}$ & $\begin{array}{c}22(52 \%) \\
13(31 \%) \\
4(10 \%) \\
3(7 \%)\end{array}$ & $\begin{array}{l}9(43 \%) \\
7(33 \%) \\
3(14 \%) \\
2(10 \%)\end{array}$ & $\begin{array}{l}13(62 \%) \\
6(29 \%) \\
1(5 \%) \\
1(5 \%)\end{array}$ & 0.956 & 4.4 & 0.029 \\
\hline
\end{tabular}

EUS, endoscopic ultrasound; MPD, main pancreatic duct; SE, standard error. 
- Table 3 Interobserver agreement per feature of chronic pancreatitis.

\begin{tabular}{|c|c|c|}
\hline Features of chronic pancreatitis & $\%$ agreement between two reviewers & Interpretation of \% agreement \\
\hline $\begin{array}{l}\text { Hyperechoic foci with shadowing } \\
\text { - Head } \\
\text { - Body } \\
\text { " Tail }\end{array}$ & $\begin{array}{l}85.7 \\
90.5 \\
88.1 \\
95.2\end{array}$ & $\begin{array}{l}\text { Almost perfect agreement } \\
\text { Almost perfect agreement } \\
\text { Almost perfect agreement } \\
\text { Almost perfect agreement }\end{array}$ \\
\hline $\begin{array}{l}\text { Hyperechoic foci without shadowing } \\
\text { - Head } \\
\text { " Body } \\
\text { " Tail }\end{array}$ & $\begin{array}{l}69.0 \\
69.0 \\
85.7 \\
78.6\end{array}$ & $\begin{array}{l}\text { Substantial agreement } \\
\text { Substantial agreement } \\
\text { Almost perfect agreement } \\
\text { Substantial agreement }\end{array}$ \\
\hline $\begin{array}{l}\text { Lobularity with honeycombing } \\
\text { - Head } \\
\text { - Body } \\
\text { " Tail }\end{array}$ & $\begin{array}{l}88.1 \\
97.6 \\
88.1 \\
88.1\end{array}$ & $\begin{array}{l}\text { Almost perfect agreement } \\
\text { Almost perfect agreement } \\
\text { Almost perfect agreement } \\
\text { Almost perfect agreement }\end{array}$ \\
\hline $\begin{array}{l}\text { Lobularity without honeycombing } \\
\text { - Head } \\
\text { " Body } \\
\text { " Tail }\end{array}$ & $\begin{array}{l}71.4 \\
83.3 \\
71.4 \\
83.3\end{array}$ & $\begin{array}{l}\text { Substantial agreement } \\
\text { Almost perfect agreement } \\
\text { Substantial agreement } \\
\text { Almost perfect agreement }\end{array}$ \\
\hline $\begin{array}{l}\text { Cysts } \\
\text { " Head } \\
\text { " Body } \\
\text { " Tail }\end{array}$ & $\begin{array}{l}92.9 \\
95.2 \\
92.9 \\
85.7\end{array}$ & $\begin{array}{l}\text { Almost perfect agreement } \\
\text { Almost perfect agreement } \\
\text { Almost perfect agreement } \\
\text { Almost perfect agreement }\end{array}$ \\
\hline $\begin{array}{l}\text { Stranding } \\
\text { - Head } \\
\text { - Body } \\
\text { - Tail }\end{array}$ & $\begin{array}{l}59.5 \\
52.4 \\
83.3 \\
85.7\end{array}$ & $\begin{array}{l}\text { Moderate agreement } \\
\text { Moderate agreement } \\
\text { Almost perfect agreement } \\
\text { Almost perfect agreement }\end{array}$ \\
\hline $\begin{array}{l}\text { MPD calculi } \\
\text { - Head } \\
\text { - Body } \\
\text { - Tail }\end{array}$ & $\begin{array}{l}100.0 \\
100.0 \\
100.0 \\
100.0\end{array}$ & $\begin{array}{l}\text { Perfect agreement } \\
\text { Perfect agreement } \\
\text { Perfect agreement } \\
\text { Perfect agreement }\end{array}$ \\
\hline $\begin{array}{l}\text { Irregular MPD contour } \\
\text { - Body } \\
\text { - Tail }\end{array}$ & $\begin{array}{r}97.6 \\
100.0 \\
97.6\end{array}$ & $\begin{array}{l}\text { Almost perfect agreement } \\
\text { Perfect agreement } \\
\text { Almost perfect agreement }\end{array}$ \\
\hline $\begin{array}{l}\text { Dilated side branches } \\
\text { - Body } \\
\text { " Tail }\end{array}$ & $\begin{array}{l}83.3 \\
92.9 \\
88.1\end{array}$ & $\begin{array}{l}\text { Almost perfect agreement } \\
\text { Almost perfect agreement } \\
\text { Almost perfect agreement }\end{array}$ \\
\hline $\begin{array}{l}\text { MPD dilatation } \\
\text { - Body } \\
\text { - Tail }\end{array}$ & $\begin{array}{r}97.6 \\
100.0 \\
97.6\end{array}$ & $\begin{array}{l}\text { Almost perfect agreement } \\
\text { Perfect agreement } \\
\text { Almost perfect agreement }\end{array}$ \\
\hline $\begin{array}{l}\text { Hyperechoic MPD margin } \\
\text { " Body } \\
\text { " Tail }\end{array}$ & $\begin{array}{l}71.4 \\
78.6 \\
83.3\end{array}$ & $\begin{array}{l}\text { Substantial agreement } \\
\text { Substantial agreement } \\
\text { Almost perfect agreement }\end{array}$ \\
\hline Overall (taken together all 29 items above) & 83.3 & Almost perfect agreement \\
\hline
\end{tabular}

\section{Discussion}

This study shows CP features to be highly prevalent in asymptomatic participants in PDAC surveillance, with a substantial to almost perfect interobserver agreement. Also, these features hardly changed over a 3-year course of follow-up.

Since the start of our PDAC surveillance program in 2008, features of CP were often detected, but their clinical relevance was unclear. They have been associated with incipient or emerging PanIN and IPMN lesions producing lobular parenchymal atrophy resulting in CP-like changes $[16,17]$. Therefore, to assess detection of features of $C P$, interobserver agreement for these features, factors associated with them, and above all, the natural course of these features over time during EUSbased surveillance for PDAC in high-risk individuals, we conducted this blinded single-center study in which we reviewed stored videos from EUS examinations in 2012 and 2015.

In our series, we showed CP features to be highly prevalent: $86 \%$ (in 2012) and $81 \%$ (in 2015) of individuals had an EUS feature of CP; only $52 \%$ of individuals fell into the category "nor- 
- Table 4 Univariate and multivariate analyses for factors possibly associated with a mean $\geq 4$ features of chronic pancreatitis

\begin{tabular}{|l|l|l|}
\hline Factors & $\begin{array}{l}\text { Univariate analyses } \\
\text { P value }\end{array}$ & $\begin{array}{l}\text { Multivariate analysis } \\
\text { P value }\end{array}$ \\
\hline Sex & 0.546 & 0.999 \\
\hline Age & 0.504 & 0.625 \\
\hline Body mass index & 0.646 & \\
\hline Underlying gene mutation & 0.890 & 0.938 \\
\hline Number of relatives affected by PDAC & 0.388 & 0.367 \\
\hline Age of youngest relative affected by PDAC & 0.002 & 0.677 \\
\hline Smoking & 0.574 & \\
\hline Number of pack years of smoking & 0.371 \\
\hline Alcohol consuming & 0.849 \\
\hline Number of alcohol units per week & 0.691 \\
\hline PDAC, pancreatic ductal adenocarcinoma. & & \\
\hline
\end{tabular}
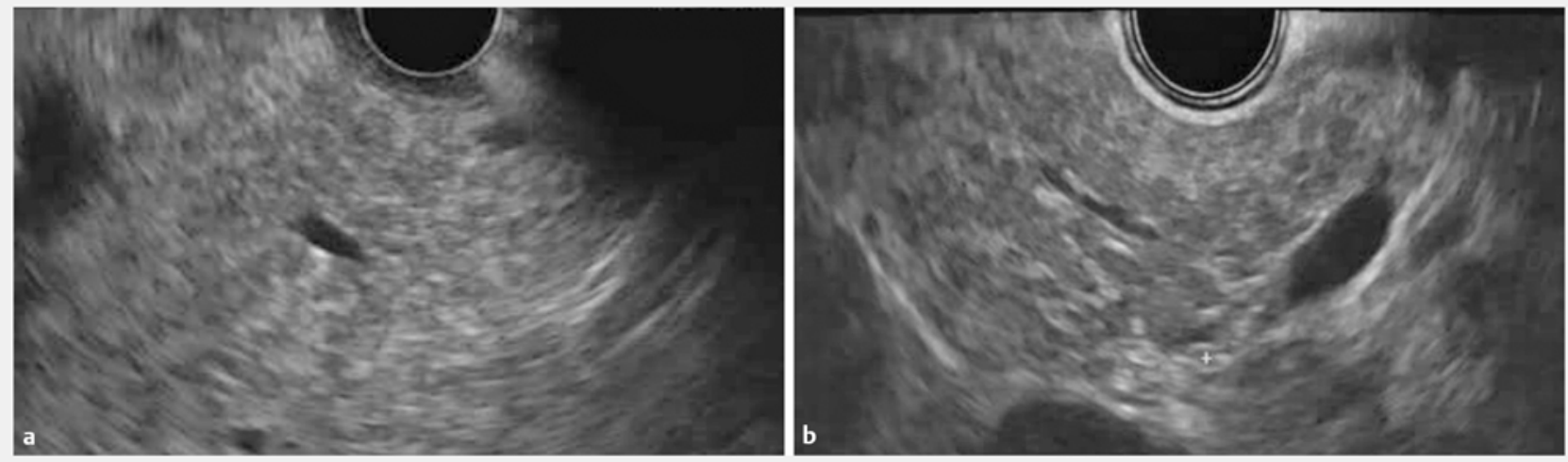

- Fig. 1 Serial still images of endosonography in a participant with marked progression of features of chronic pancreatitis. a Still image of the endoscopic ultrasound examination in 2012, showing an unremarkable pancreas. b Still image of the endoscopic ultrasound examination in 2015 in the same individual, showing multiple features of chronic pancreatitis (hyperechoic foci, lobularity, stranding, and a hyperechoic main pancreatic duct margin).

mal" when the Rosemont classification [18] was applied. This prevalence is much higher than described in a non-high-risk cohort. Petrone et al. [20] described $16.8 \%$ of asymptomatic individuals undergoing EUS for an indication not related to pancreatico-biliary disease as having at least one ductal or parenchymal abnormality present. As the prevalence of CP features in our cohort at high risk of developing PDAC is this high, the alleged association between (progression) of specific EUS features and presence of PanIN or IPMN lesions bears particular interest.

Assessing the intra-individual change in $\mathrm{CP}$ features over our 3-year study period, the number of $C P$ features, individual $C P$ features and Rosemont classification did not change, except for a statistically significant intra-individual decrease in hyperechoic foci without shadowing. However, development and progression of precursor lesions into PDAC may take multiple years
[21]. Continued follow-up of these individuals therefore is of pivotal importance. Eventually, pathological examination of resected pancreatic specimens, not yet available from individuals in the current study, are needed to further clarify the association and clinical relevance of EUS detection of CP features.

Our study revealed no baseline factors significantly associated with detection of a mean of $\geq 4$ CP features. Even factors that are known to be associated with $C P$, including smoking and alcohol consumption [22,23], were not associated with detection of CP features in our cohort. Although speculative, this could be related to the underlying pathophysiologic mechanism of chronic pancreatitis-like changes in individuals at high risk of developing pancreatic cancer. Studies suggest that (multifocal) PanIN and IPMN lesions produce obstructive lobular atrophy or the pancreatic parenchyma which is likely the source of the CP-like changes that follow in these patients $[16,17]$. 
Our analyses into interobserver agreement for detection of $\mathrm{CP}$ features showed an excellent agreement for most of the CP features. Overall agreement between the two expert endosonographers was $83 \%$ and rated as almost perfect. This is somewhat better than described in previous reports where a moderate to substantial agreement was described [24-26] (kappavalues of $0.46,0.65$ and agreement of $68 \%$, respectively). Our high interobserver agreement might be explained by the fact that our two reviewers are highly trained and experienced endosonographers.

To our knowledge, this is the first study to longitudinally assess features of CP in asymptomatic high-risk individuals participating in an EUS-based PDAC surveillance program. Another strength of this study is that two expert endosonographers reviewed the EUS recordings in a blinded fashion using a standardized case record form. However, this study also has some limitations. The number of participants was limited and the follow-up comprised 3 years. None of the participating individuals underwent surgery and we therefore lack definite diagnoses and pathological correlates. Consequently, it is not possible to determine the clinical relevance of the different EUS features of $\mathrm{CP}$ that were detected. Also, the Rosement classification was applied in our cohort. This classification was not designed for the purpose of diagnosing $\mathrm{CP}$ in asymptomatic patients at high risk of developing PDAC. Although individual criteria can be readily applied and followed in an asymptomatic cohort of high-risk individuals undergoing PDAC surveillance, its clinical relevance in this setting remains unclear. The total score also may be less relevant than development of individual features over time.

\section{Conclusion}

In conclusion, this blinded study, reviewing EUS videos of asymptomatic high-risk individuals participating in EUS-based PDAC surveillance, showed features of $C P$ to be highly prevalent but stable over a 3-year period, with high interobserver agreement. We could not associate any baseline factors with detection of these CP features. Longer follow-up and, if available, pathological examination of pancreatic resection specimens will be essential to understanding the relationship between these CP features and development of malignancy, and whether detection of these features bears clinical relevance, for example, in setting the indication for resection or serving as a criterion of influence in determining the screening interval.

\section{Competing interests}

None

\section{References}

[1] Schneider R, Slater EP, Sina M et al. German national case collection for familial pancreatic cancer ( $\mathrm{FaPaCa})$ : ten years experience. Fam Cancer 2011; $10: 323-330$
[2] Canto MI, Hruban RH, Fishman EK et al. Frequent detection of pancreatic lesions in asymptomatic high-risk individuals. Gastroenterology 2012; 142: 796 - 804; quiz e714-795

[3] Kimmey MB, Bronner MP, Byrd DR et al. Screening and surveillance for hereditary pancreatic cancer. Gastrointestinal endoscopy 2002; 56 : S82- 86

[4] Canto MI, Goggins M, Yeo C] et al. Screening for pancreatic neoplasia in high-risk individuals: An EUS-based approach. Clin Gastroenterol Hepatol 2004; 2: 606-621

[5] Canto MI, Goggins M, Hruban RH et al. Screening for Early Pancreatic Neoplasia in High-Risk Individuals: A Prospective Controlled Study. Clin Gastroenterol Hepatol 2006; 4: 766 - 781

[6] Poley JW, Kluijt I, Gouma DJ et al. The yield of first-time endoscopic ultrasonography in screening individuals at a high risk of developing pancreatic cancer. Am J Gastroenterol 2009; 104: 2175-2181

[7] Verna EC, Hwang C, Stevens PD et al. Pancreatic cancer screening in a prospective cohort of high-risk patients: A comprehensive strategy of imaging and genetics. Clin Cancer Res 2010; 16: 5028 - 5037

[8] Ludwig E, Olson SH, Bayuga S et al. Feasibility and yield of screening in relatives from familial pancreatic cancer families. Am J Gastroenterol 2011; 106: $946-954$

[9] Vasen HF, Wasser M, van Mil A et al. Magnetic resonance imaging surveillance detects early-stage pancreatic cancer in carriers of a p16Leiden mutation. Gastroenterology 2011; 140: 850-856

[10] Al-Sukhni W, Borgida A, Rothenmund H et al. Screening for pancreatic cancer in a high-risk cohort: an eight-year experience. J Gastrointest Surg 2012; 16: $771-783$

[11] Potjer TP, Schot I, Langer P et al. Variation in precursor lesions of pancreatic cancer among high-risk groups. Clin Cancer Res 2013; 19: $442-449$

[12] Harinck F, Kluijt I, Poley JW et al. Comparative yield of endosonography and magnetic resonance imaging in individuals at high-risk for pancreatic cancer. Gastroenterology 2009; 136: A147

[13] Harinck F, Konings IC, Kluijt I et al. A multicentre comparative prospective blinded analysis of EUS and MRI for screening of pancreatic cancer in high-risk individuals. Gut 2016; 65: 1505-1513

[14] Canto MI, Harinck F, Hruban RH et al. International cancer of the pancreas screening (CAPS) consortium summit on the management of patients with increased risk for familial pancreatic cancer. Gut 2013; 62: $339-347$

[15] Konings ICAW, Harinck F, Poley JW et al. Surveillance of individuals at high risk to develop pancreatic cancer: where do we stand. Am Oncol Hematol Rev; 2014: 70 - 79

[16] Brune K, Abe T, Canto M et al. Multifocal neoplastic precursor lesions associated with lobular atrophy of the pancreas in patients having a strong family history of pancreatic cancer. Am J Surg Pathol 2006; 30 : $1067-1076$

[17] Aimoto T, Uchida E, Nakamura Y et al. Multicentric pancreatic intraepithelial neoplasias (PanINs) presenting with the clinical features of chronic pancreatitis. J Hepatobiliary Pancreat Surg 2008; 15: 549 553

[18] Catalano MF, Sahai A, Levy M et al. EUS-based criteria for the diagnosis of chronic pancreatitis: the Rosemont classification. Gastrointest Endosc 2009; 69: 1251 - 1261

[19] Landis JR, Koch GG. The measurement of observer agreement for categorical data. Biometrics 1977; 33: 159-174

[20] Petrone MC, Arcidiacono PG, Perri F et al. Chronic pancreatitis-like changes detected by endoscopic ultrasound in subjects without signs of pancreatic disease: do these indicate age-related changes, effects of xenobiotics, or early chronic pancreatitis? Pancreatology 2010; 10 : $597-602$

[21] Yachida S, Iacobuzio-Donahue CA. Evolution and dynamics of pancreatic cancer progression. Oncogene 2013; 32: 5253 - 5260 
[22] Irving HM, Samokhvalov AV, Rehm J. Alcohol as a risk factor for pancreatitis. A systematic review and meta-analysis. JOP 2009; 10: 387 392

[23] Andriulli A, Botteri E, Almasio PL et al. Smoking as a cofactor for causation of chronic pancreatitis: a meta-analysis. Pancreas 2010; 39: $1205-1210$

[24] Del Pozo D, Poves E, Tabernero S et al. Conventional versus Rosemont endoscopic ultrasound criteria for chronic pancreatitis: interobserver agreement in same day back-to-back procedures. Pancreatology 2012; 12: $284-287$
[25] Stevens T, Lopez R, Adler DG et al. Multicenter comparison of the interobserver agreement of standard EUS scoring and Rosemont classification scoring for diagnosis of chronic pancreatitis. Gastrointest Endosc 2010; 71: 519-526

[26] Kalmin B, Hoffman B, Hawes R et al. Conventional versus Rosemont endoscopic ultrasound criteria for chronic pancreatitis: comparing interobserver reliability and intertest agreement. Can J Gastroenterol 2011; 25: $261-264$ 